\title{
isomiRs-Hidden Soldiers in the miRNA Regulatory Army, and How to Find Them?
}

\author{
Ilias Glogovitis ${ }^{1,2}$, Galina Yahubyan ${ }^{1}$, Thomas Würdinger ${ }^{2}$, Danijela Koppers-Lalic ${ }^{2}$ and Vesselin Baev ${ }^{1, *(D)}$ \\ 1 Faculty of Biology, University of Plovdiv, Tzar Assen 24, 4000 Plovdiv, Bulgaria; ilias@uni-plovdiv.bg (I.G.); \\ gyahubyan@uni-plovdiv.bg (G.Y.) \\ 2 Department of Neurosurgery, Cancer Center Amsterdam, Amsterdam University Medical Centers, VU \\ University Medical Center, De Boelelaan 1117, 1081 HV Amsterdam, The Netherlands; \\ t.wurdinger@amsterdamumc.nl (T.W.); d.lalic@amsterdamumc.nl (D.K.-L.) \\ * Correspondence: baev@uni-plovdiv.bg
}

Citation: Glogovitis, I.; Yahubyan, G.; Würdinger, T.; Koppers-Lalic, D.;

Baev, V. isomiRs-Hidden Soldiers in the miRNA Regulatory Army, and How to Find Them? Biomolecules 2021, 11, 41. https://doi.org/ 10.3390/biom11010041

Received: 27 November 2020 Accepted: 26 December 2020 Published: 30 December 2020

Publisher's Note: MDPI stays neutral with regard to jurisdictional clai$\mathrm{ms}$ in published maps and institutional affiliations.

Copyright: (C) 2020 by the authors. Licensee MDPI, Basel, Switzerland. This article is an open access article distributed under the terms and conditions of the Creative Commons Attribution (CC BY) license (https:// creativecommons.org/licenses/by/ $4.0 /)$.
Abstract: Numerous studies on microRNAs (miRNA) in cancer and other diseases have been accompanied by diverse computational approaches and experimental methods to predict and validate miRNA biological and clinical significance as easily accessible disease biomarkers. In recent years, the application of the next-generation deep sequencing for the analysis and discovery of novel RNA biomarkers has clearly shown an expanding repertoire of diverse sequence variants of mature miRNAs, or isomiRs, resulting from alternative post-transcriptional processing events, and affected by (patho)physiological changes, population origin, individual's gender, and age. Here, we provide an in-depth overview of currently available bioinformatics approaches for the detection and visualization of both mature miRNA and cognate isomiR sequences. An attempt has been made to present in a systematic way the advantages and downsides of in silico approaches in terms of their sensitivity and accuracy performance, as well as used methods, workflows, and processing steps, and end output dataset overlapping issues. The focus is given to the challenges and pitfalls of isomiR expression analysis. Specifically, we address the availability of tools enabling research without extensive bioinformatics background to explore this fascinating corner of the small RNAome universe that may facilitate the discovery of new and more reliable disease biomarkers.

Keywords: isomiRs; microRNAs; NGS; tools; data analysis

\section{Multi-Layered $m i R$ Gene Control as a Source of Plentiful miRNA Sequence Variations}

MicroRNAs (miRNAs) were discovered in the soil-dwelling nematode Caenorhabditis elegans to mediate its temporal pattern formation [1,2]. Since then, thousands of miRNAs have been identified and characterized in animals, plants, and some animal viruses [3]. The latest release of the miRNA repository miRBase (v22) contains 1917 human hairpin precursors and 2654 mature sequences [4]. MiRNAs are thought to collectively regulate one-third of human genes, thereby acting as key regulators of development, cell differentiation, and homeostasis [5].

Most miRNAs are typically 21-24 nt in length and encoded by their own genes (MIR genes). The encoding loci of some miRNAs reside in introns or untranslated regions of protein-coding genes, as well as in introns or exons of non-coding RNAs [6,7]. Certain miRNA genes have been found clustered and being transcribed as monocistronic or polycistronic transcripts [8].

\subsection{Canonical miRNA Biogenesis Pathway}

MIR genes are transcribed in a manner similar to protein-coding genes by RNA polymerase-II (Pol II), and occasionally by RNA polymerase III (Pol III) to yield primary miRNAs (pri-miRNAs) and undergo multistep processing $[9,10]$. 
Each pri-miRNA forms a hairpin-shaped structure which is processed further by a microprocessor complex, consisting of one molecule of the ribonuclease III (RNase III) enzyme Drosha and two molecules of DGCR8 (Di George Syndrome critical region gene 8) [11]. DGCR8 directs Drosha to the double stranded RNA (dsRNA)-single stranded RNA (ssRNA) junction on the pri-miRNAs to cleave $11 \mathrm{bp}$ away from the junction releasing $\sim 50-80 \mathrm{nt}$ long precursor miRNAs (pre-miRNAs). The newly produced pre-miRNA is transported to the cytoplasm via exportin-5 [10] and RAN-GTP [12-14].

The RNase III enzyme Dicer, together with the dsRNA-binding proteins TRBP (transactivation response element RNA-binding protein) and/or PACT (protein activator of the interferon-induced protein kinase), then further cleaves pre-miRNA to generate a short double-stranded RNA fragment [15-17]. The miRNA duplex has a $\sim 2$ nt 3'overhangs produced by the consecutive cleavage of Drosha and Dicer $[18,19]$. Once formed, the duplex is loaded into an Argonaute (AGO) protein where one of the duplex strands is retained (guide strand, $\mathrm{miR}$ ) and the other is expelled and degraded (passenger strand, $\mathrm{miR}^{*}$ ) [20]. Usually, the retained strand is the one that has the less stably base-paired $5^{\prime}$ end in the duplex $[21,22]$ and usually with a $5^{\prime}$-terminal pU or pA $[23,24]$.

In humans, the AGO family comprises four family members (Ago1-4), of which the Ago2 is the most abundant [25]. AGO and the retained ssRNA form the mature miRNAinduced silencing complex (miRISC). Recently, it was reported that the half-lives of miR and $\mathrm{miR}^{*}$ strands for some miRNA duplexes were similar, indicating similar loading onto miRISC [26].

\subsection{Non-Canonical miRNA Biogenesis Pathways}

Dicer-independent pathway: Like the canonical pathway, the first cleavage step of miRNA processing is carried out by Drosha and results in hairpin-shaped pre-miRNA. There are examples such as that of miR-451, in which Drosha cleavage yields a short premiRNA (42 nt) with only a $17 \mathrm{nt}$ stem that is of insufficient length to be a Dicer substrate [27]. Unlike the canonical pathway, the entire pre-miRNA instead of binding to Dicer is loaded on AGO2, which is the only one of all AGO proteins that has a slicer activity, and the second cleavage step of the $3 p$ strand is performed followed by $3^{\prime}-5^{\prime}$ trimming to complete the miR-451 maturation [28,29].

Drosha-independent pathway: The best characterized Drosha-independent miR biogenesis pathway is that of mirtrons-introns with hairpin potential [30-32]. Unlike the canonical pathway, pre-miRNA-like hairpins are generated by the splicing machinery and lariat-debranching enzyme, without the need for Drosha's involvement [30,31].

\subsection{IsomiR Biogenesis Pathways}

It has long been thought that each arm of the pre-miRNA produces one miRNA ( $\mathrm{miR}$ and $\mathrm{miR}^{*}$ ). High-throughput sequencing has revealed a variety of mature miRNA forms called isomiRs that are produced from a single pre-miRNA and differ in length, sequence or both [33-37]. Small RNA databases annotate one "mature sequence" per premiRNA arm, which is usually the most frequent sequence across all deposited sequences at the time of entry into the database [38]. Appropriately, it has been suggested by Desvignes and colleagues (2015) to designate this molecule as "reference sequence miRNA" (RefSeqmiRNA) to which any newly identified variant is assigned. The number of microarray and sequencing assays of healthy and pathological human tissue have revealed specific isomiRs that are substantially more abundant than the RefSeq-miRNA (Figure 1) $[39,40]$. 


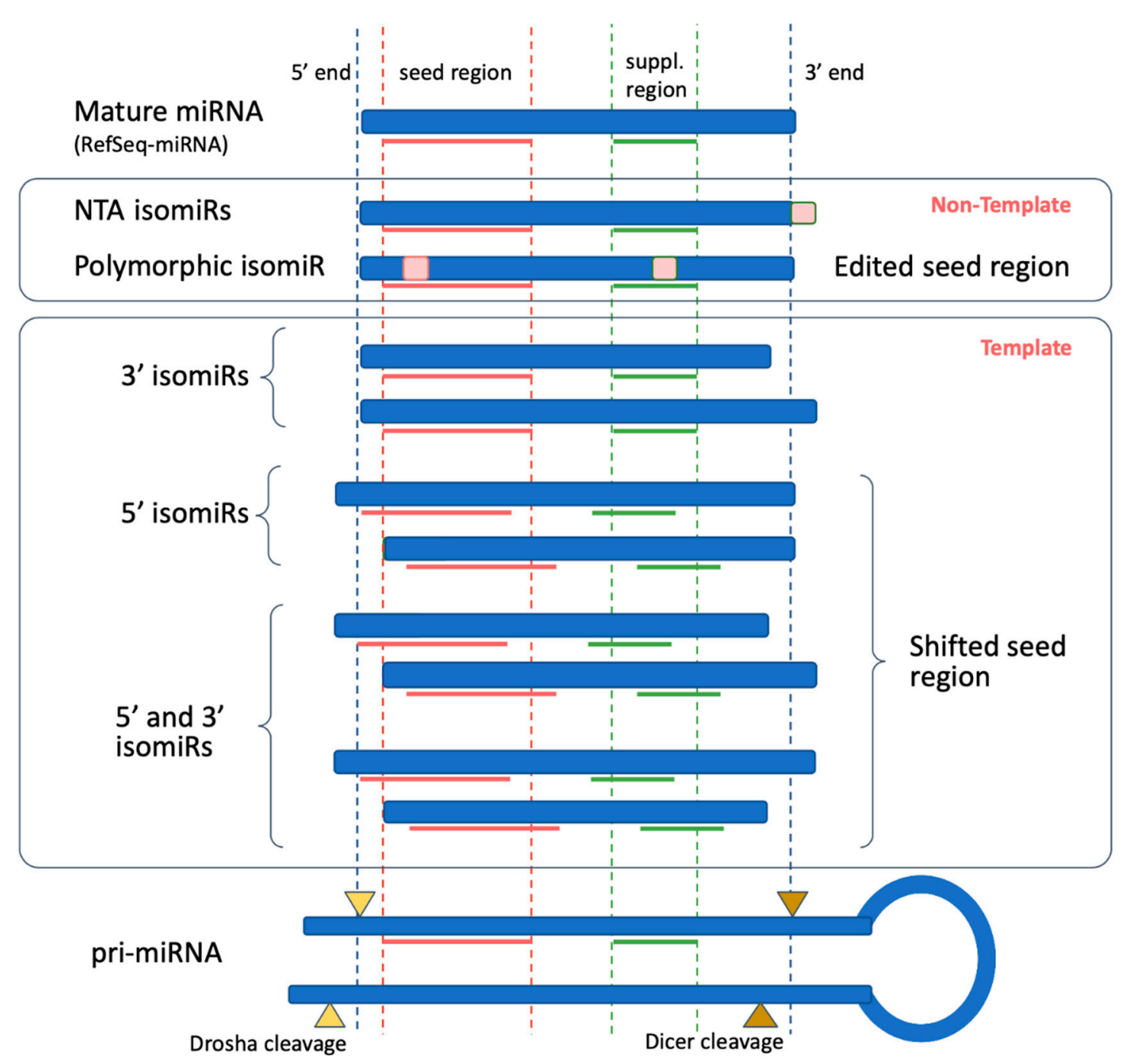

Figure 1. Length and sequence variations of isomiRs associated with the mature microRNA (miRNA) sequence (reference sequence, RefSeq) in miRBase.

Depending on the degree of matching with pri-miRNA, isomiRs are classified as template (if there is a complete match with pri-miRNA) or non-template (if the match with pri-miRNA is not complete isomiRs. Regarding the template isomiRs, comparing the locations of the RefSeq and the isomiR sequence on the pri-miRNA shows whether the $5^{\prime}-, 3^{\prime}-$, or both ends are shifted simultaneously. $5^{\prime}$-isomiRs, and some of the polymorphic isomiRs, have an altered seed region, and so may target different mRNA molecules.

Alternative cleavage by Drosha and/or Dicer generates templated isomiRs with variable $5^{\prime}$ and/or $3^{\prime}$ ends: IsomiRs production is attributed mainly to imprecise or modulated variations in cleavage by Drosha and/or Dicer during miRNA biogenesis [35]. The selection of cleavage sites by the two RNase III enzymes defines the miRNA $5^{\prime}$ - and $3^{\prime}$-ends. Drosha and Dicer recognize specific pri-RNA and pre-RNA structural modules and sequence motifs that set the cleavage distance [41,42]. Some pri-miRNAs are processed by Drosha at multiple sites, producing more than one pre-miRNA and mature miRNA species from a single primary transcript $[43,44]$. Dicer's activity can be modulated by its partner proteins TRBP and PACT. Competing for Dicer binding, under different conditions or in different cell types, TRBP and PACT can control dsRNA recruitment, relative orientation, and conformational changes, and thus isomiR production [17]. 
Non-templated nucleotide additions (NTA) produce $3^{\prime}$-tailed isomiRs: NTA mainly involves adenylation or uridylation at miRNA $3^{\prime}$-ends by multiple terminal nucleotidyl transferases [45]. Mono- and oligo-adenylation is carried out by the poly(A) RNA polymerase (PAP) associated domain-containing proteins PAPD4 (also known as GLD2) and PAPD5 [46-49]. Uridylation of miRNAs and their sequence variants can be mediated by terminal uridylyl transferases (TUTases) including TUT4 and TUT7 (also known as Zcchc11 and Zcchc6, respectively) in humans [50-53]. In hsa-let-7 biogenesis, the switch from mono- to oligo-uridylation of pre-let-7 is controlled by the RNA-binding protein Lin28 and represses the expression of mature let-7 [50,51].

A-to-I modification of the sequence of miRNA precursor creates edited miRNA sequence variants: Other miRNA isoforms are also generated from adenosine-to-inosine (A-to-I) RNA-editing by adenosine deaminase acting on RNA-ADARs (ADAR1 and ADAR2 in mammals) which can recognize the double-stranded structure of pri-miRNAs [54]. A-to-I modifications of pri-miRNA can interfere with the pri-miRNA and/or pre-miRNA processing [54] and lead to miRNA sequence variations [55]. Since inosine I is recognized as guanosine (G) [56], editing of the miRNA seed (at positions 2-7) can redirect the miRNA to a new set of targets [55].

\subsection{Mode of miRNA Action (miRNA Mediated Gene Expression Regulation)}

MiRISC is the effector complex of miRNA-mediated gene expression regulation, where miRNAs function as a specificity determinant while AGO exerts the regulatory effect [57]. MiRNAs have a predominantly inhibitory effect on the expression of their effector genes, and rarely positive, acting at both the post-transcriptional and transcriptional levels.

Most studies have shown that canonically, miRNAs guide miRISC to a specific target mRNA through sequence-specific base pairing with complementary sites present in the 3 '-untranslated region (UTR) [58]. AGO recruits a member of the glycine-tryptophan (GW) protein family (TNRC6A/GW182, TNRC6B, and TNRC6C in humans) [59], which in turn interacts with other effector proteins to cause mRNA decay or translation repression [60-62].

Some studies have revealed activating regulation of gene expression by miRNAs. During the miRNA-mediated enhancement of translation, AGO2 interacts with FXR1 (fragile X mental retardation protein 1) instead of GW182 as it was shown in quiescent cells and oocytes $[63,64]$. Activating miRNA was found to bind to $3^{\prime}$ UTR [65] as well as to $5^{\prime}$ UTR [66].

The number of studies reporting nucleus-enriched miRNA with functional significance is increasing. In the nucleus, miRNAs are thought to act co-/post-transcriptionally regulating target mRNA stability of and splicing events or may regulate transcription directly by inducing epigenetic alterations at specific gene promoters.

\subsection{IsomiR Biological Implication}

IsomiR variations can differ between tissue types, disease states, and change across developmental time $[39,67] .3^{\prime}$ isomiRs, the most abundant miRNA sequence variants, can exhibit mainly altered stability [46,68], and sub-cellular localization [69,70], and are less likely to affect target selection [71]. Both $5^{\prime}$ isomiRs and A-to-I edited variants can have altered seed region and so may target the same or different mRNA molecules and biological pathways compared to the corresponding RefSeq-miRNA [55,72-74]. 


\section{Bioinformatics Approaches of Identifying and Analyzing miRNA and isomiR Molecules}

Beyond quantitative evaluation, next-generation sequencing (NGS) allows for singlebase resolution of known and novel miRNAs, and it is currently used to identify contextspecific miRNA species in samples. For analyzing small RNA (sRNA) NGS data, a variety of bioinformatics tools have been developed allowing profiling the miRNA repertoire, discovering new potential miRNAs as well as identification of their isoforms. In the beginning of miRNA profiling era, the detected $5^{\prime}$ - and $3^{\prime}$-sequence variations were treated as artifacts and discarded from the downstream analysis $[75,76]$. However, miRNA sequence variation phenomenon was quickly acknowledged as part of the comprehensive miRNA biogenesis landscape $[45,77,78]$. Thus these length and sequence variants were named isomiRs, and gradually became the main objectives for the miRNA analysis software [33]. For the past decade, many tools have been specifically tailored to miRNA analysis but exploring them in-depth shows quite different performances in terms of sensitivity and accuracy levels as well as used methods, workflows, and processing steps, and at the end output datasets have variable overlapping. In this regard, many issues remain bioinformatics challenges, such as (i) the nature of sRNAs being that they are a quite small molecule and mapping procedure can lead to mapped sequence at the wrong location, and (ii) some MIR genes having duplication which can lead to difficulties on the analysis steps.

Almost all analyzing tools of miRNA NGS data are performed using Linux/Unix servers or clusters. However, analyzing and outputting results in Linux is difficult for most biology scientists. Furthermore, the process steps of the analysis include command line workflows and produce large amounts of data and files that are difficult to perform and interpret. It is therefore quite important to develop efficient tools that have a user-friendly GUI (graphic user interface) and good visualizations that provide better human-readable summarization of the results. On the other hand, there are two major problems with implementing such tools: (i) web-based tools have some restrictions, such as limited data upload, providing data on a lab-external computer, and the tool access and support depend largely on the author, and (ii) stand-alone programs may require extra steps by the user to run and fulfill the requirements, and may also be quite overwhelming in terms of computer power.

There are also challenges regarding the specificity of the detection of isomiRs due to their heterogeneous origin. Several combinations of $5^{\prime}$ and $3^{\prime}$ trimmed and tailed, templated and non-templated, isomiRs can exist at once, making the overall analysis more complex. Development of a single algorithm capable of processing all detectable miRNA variants as isomiRs can be nearly impossible [79]. Several in silico software tools already support isomiR identification at different levels. Nevertheless, among them, there is a lack of consensus on isomiR classification and nomenclature. Furthermore, some tools are only able to partially identify the repertoire of isomiRs or perform only isomiR discovery without the capability of extracting differentially expressed isoforms.

As there is no consensus on the steps for analyzing miRNAs and their isoforms, we present here a summary diagram of the major processing steps used in most tools for identification and/or analysis of isomiR in sRNA-seq datasets (Figure 2). Most of the tools (CBS-miRSeq, iMir, SRNAnalyser, MIRPIPE, MiRge, QuickMIRSeq, MirDis, Jasmine, miRMaster, OptimiR, and Prost!), always include a pre-processing step in which the raw reads are quality checked, trimmed, and cleaned, allowing reads to be used in the next steps. Widely accepted external tools for this step are, for example, FastQC, Cutadapt, and Trimommatic. In the next step, these clean sRNA reads have to be mapped on the reference database. For the specifics of isomiR identification, and the study of the sequence variant set that a particular miRNA has, the reference database can be the pre-miRNA database (usually using miRBase and miRGene), reference genome, or custom-made database. For this step, a wide range of tools are developed on top of the widely used Bowtie aligner. Few tools, such as miRPro and Chimira, use Novoalign and BLAST as mappers and specifically created custom aligners (CASMIR, isomiR-SEA). Firstly, the reference sequence of the mature miRNA is localized on the pre-miRNA and then all other molecules that map to a 
defined region comprising miRNA site can be explored to detect all types of $3^{\prime}$ and $5^{\prime}$ offset and modified sRNAs thus allowing a precise isomiR classification. Some tools use a different approach by creating a custom database with miRNA seed/motif sequences that are subsequently used for the mapping (for example, isomiR-SEA, QuagmiR). It is important to note that since there is a lack of consensus on isomiR nomenclature and classification, some tools do not provide a detailed and comprehensive analysis of individual isomiRs but rather explore the patterns in the whole subset of molecules. For this reason, only a few tools provide a comprehensive analysis of specific differentially expressed isomiRs in multiple samples (Table 1). When it comes to differential expression analysis, the majority of the developed software tools use external dedicated statistical packages like DESeq2 and EdgeR (iMir, miR-isomiRExp, CSB-miRSeq, sRNAtoolbox, miRpro, miRDis, Chimira, etc), or RPM normalization (DeAnniso, IsomiRage). Overall, a few tools provide distinctive features such as comprehensive isomiR profile exploration (for example CASMIR, miRMaster, IsomiR-SEA, Chimera), isomiR nomenclature (Jasmine), or even differential expression profiles and analysis at the level of a single isomiR across samples (DeAnniso, MIR-isomiRexp). Some programs additionally provide other well implemented distinctive features such as miRNA arm switching detection, isomiR analysis independent of miRNA locus, target alteration analysis, etc. (Table 1).

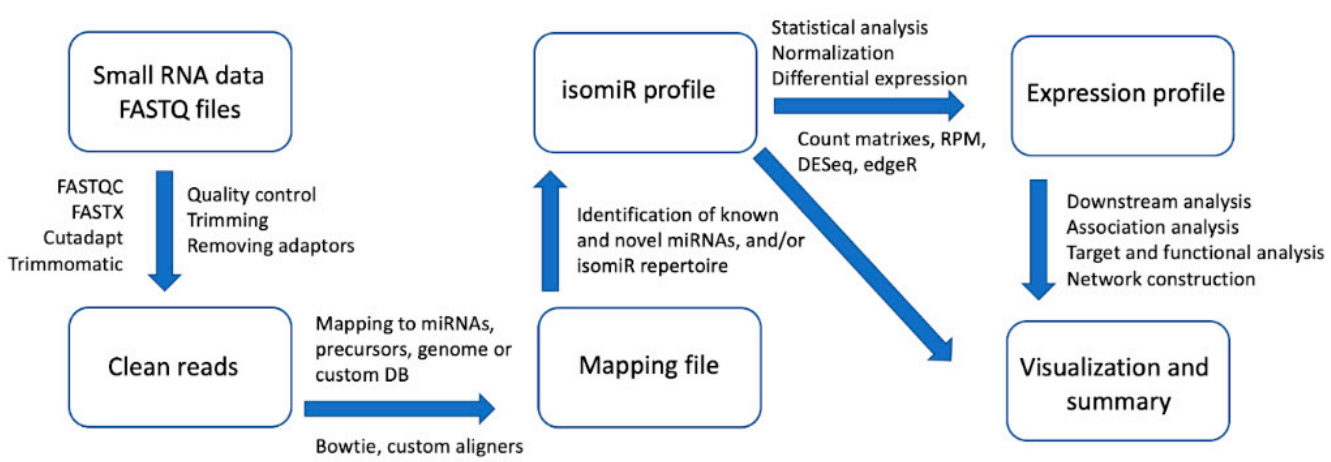

Figure 2. General summary of the workflow used in miRNA and isomiR analysis tools.

Due to the variety of the output files of commonly used tools, comparisons between the results of different tools are not accurate. The miRNA Transcriptomic Open Project (miRTOP) overcomes the above problem by generating a new file format miRGFF3 from the most state-of-the-art tools output files (e.g., sRNAbench, Prost!, and OptimiR). It can also convert miRGFF3 into other formats as FASTA and VCF, allowing users to continue with various analyses without being limited to only one tool.

In terms of implementation, most of the tools are web-based, providing a user-friendly interface, but limiting data size and future support, including access, are strictly dependent on the developing team. Others offer standalone tools for different operating systems (OS), but this option assumes that the user must install the tool him/herself and meet the requirements and dependencies to operate. Very few tools, for example, provide Docker images that can discard some of the mentioned disadvantages - they can provide a readyto-run, pre-configured standalone or web-based tool that can run on a user's computer or server, regardless of OS. 


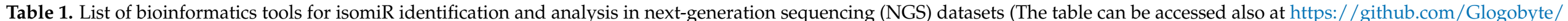
isomiR_tools).

\begin{tabular}{|c|c|c|c|c|c|c|}
\hline Tool Name & Type & Tool Features & Year & Authors & Journal/URL & $\begin{array}{l}\text { Reference } \\
\text { (DOI Number) }\end{array}$ \\
\hline miRMaster & Web & $\begin{array}{l}\text { - Quantification of miRNAs and } \\
\text { - } \quad \text { Discon-coding RNAs. } \\
\text { - } \quad \text { Quantification on known and novel miRNA } \\
\text { with miRDeep2. } \\
\text { - } \quad \text { Pre-processing (adapter trimming, quality } \\
\text { filtering, read collapsing). } \\
\text { - Mapping with Bowtie to various ncRNA } \\
\text { (rRNAs, snRNAs, snoRNAs, scaRNAs, lincRNAs, } \\
\text { piRNAs, tRNAs). } \\
\text { Exogenous miRNAs mapping with bacteria } \\
\text { and viruses. } \\
\text { Used for validation of used samples from lung } \\
\text { and blood samples. }\end{array}$ & 2017 & Tobias Fehlmann et al. & $\begin{array}{l}\text { Nucleic Acids Research } \\
\text { Open Access } \\
\text { https://www.ncbi.nlm. } \\
\text { nih.gov/pmc/articles/ } \\
\text { PMC5587802/ }\end{array}$ & $\begin{array}{l}\text { 10.1093/nar/gkx595 } \\
{[80]}\end{array}$ \\
\hline QuickMIRSeq & Linux & $\begin{array}{l}\text { - } \quad \text { Quantify miRNAs and isomiRs. } \\
\text { Avoidance of multiple mapping issue of reads of } \\
\text { identical sequences. } \\
\text { - Clustering and grouping of identical and similar } \\
\text { sequences. } \\
\text { Trimming adapters, collapsing, joint mapping } \\
\text { with Bowtie. } \\
\text { Remapping reads with mismatches to a reference } \\
\text { genome to further reduce the number of } \\
\text { false hits. }\end{array}$ & 2017 & Shanrong Zhao et al. & $\begin{array}{l}\text { BMC Bioinformatics } \\
\text { Open Access } \\
\text { https:/ / www.ncbi.nlm. } \\
\text { nih.gov/pmc/articles/ } \\
\text { PMC5359966/ }\end{array}$ & $\begin{array}{l}\text { 10.1186/s12859-017-1601-4 } \\
{[81]}\end{array}$ \\
\hline
\end{tabular}


Table 1. Cont.

\begin{tabular}{|c|c|c|c|c|c|c|}
\hline Tool Name & Type & Tool Features & Year & Authors & Journal/URL & $\begin{array}{l}\text { Reference } \\
\text { (DOI Number) }\end{array}$ \\
\hline iMir & $\begin{array}{l}\text { Linux } \\
\text { Mac }\end{array}$ & $\begin{array}{l}\text { - } \quad \text { Identification of miRNAs and other sncRNAs, } \\
\text { - } \quad \text { Adaph as piRNAs. } \\
\text { expression analysis. } \\
\text { - } \quad \text { Analysis of sncRNAs and novel miRNAs. } \\
\text { - } \quad \text { Identification of isomiRs using miRanalyzer. } \\
\text { - } \quad \text { Ssing miRAnalyzer and miRDeep2. } \\
\text { - } \quad \text { expressed sncRNAs. } \\
\text { - } \quad \text { ifferential expression using DESeq } \\
\text { - } \quad \text { Target prediction using TargetScan and miRanda. }\end{array}$ & 2013 & Giorgio Giurato et al. & $\begin{array}{l}\text { BMC } \\
\text { Bioinformatics } \\
\text { Open access } \\
\text { https: } \\
\text { //bmcbioinformatics. } \\
\text { biomedcentral.com/ } \\
\text { articles/10.1186/1471-2 } \\
\text { 105-14-362 }\end{array}$ & $\begin{array}{l}\text { 10.1186/1471-2105-14-362 } \\
{[82]}\end{array}$ \\
\hline MIR-isomiRExp & Web & $\begin{array}{l}\text { - } \quad \text { Analyze the expression patterns or } \\
\text { miRNA/isomer levels. } \\
\text { - MiRNA maturation and processing mechanism } \\
\text { at isomiRs levels. } \\
\text { - } \quad \text { Using MirBase DB, mapping with Bowtie. } \\
\text { - } \quad \text { Analysis at the isomiR levels based/independent } \\
\text { on miRNA locus. } \\
\text { - Arm-switching analysis. }\end{array}$ & 2016 & Li Guo et al. & $\begin{array}{l}\text { Scientific Reports } \\
\text { Open Access } \\
\text { https:/ / www.ncbi.nlm. } \\
\text { nih.gov/pmc/articles / } \\
\text { PMC4806314/ }\end{array}$ & $\begin{array}{l}\text { 10.1038/srep23700 } \\
{[83]}\end{array}$ \\
\hline miRNAgFree & $\begin{array}{l}\text { Linux } \\
\text { Windows }\end{array}$ & $\begin{array}{l}\text { - MiRNA prediction based on biogenesis features } \\
\text { (known } 5^{\prime} \text { homogeneity) and isomiR } \\
\text { duplex forming. } \\
\text { - Uses the sRNAbench preprocessing. }\end{array}$ & 2017 & EL Aparicio et al. & $\begin{array}{l}\text { BioRxiv } \\
\text { https://www.biorxiv. } \\
\text { org/content/10.1101/19 } \\
\text { 3094v1.full }\end{array}$ & $\begin{array}{l}10.1101 / 193094 \\
{[84]}\end{array}$ \\
\hline isomiRID & $\begin{array}{l}\text { Linux } \\
\text { Mac }\end{array}$ & $\begin{array}{l}\text { - Identification of } 5^{\prime}, 3^{\prime} \text { and polymorphic isomiRs. } \\
\text { - } \quad \text { Identification of non-templated } 5^{\prime} \text { or } 3^{\prime} \text { end } \\
\text { and variations. } \\
\text { - It could be applied to every organism } \\
\text { (plants and animals). } \\
\text { - } \quad \text { Detection of isomiRs with one mismatch. } \\
\text { Mapping in pre-miRNAs with Bowtie. }\end{array}$ & 2013 & $\begin{array}{l}\text { Luiz Felipe Valter de } \\
\text { Oliveira et al. }\end{array}$ & $\begin{array}{l}\text { Bioinformatics } \\
\text { https: } \\
\text { //academic.oup.com/ } \\
\text { bioinformatics/article/ } \\
29 / 20 / 2521 / 276800\end{array}$ & $\begin{array}{l}\text { 10.1093/bioinformatics/btt424 } \\
\text { [85] }\end{array}$ \\
\hline
\end{tabular}


Table 1. Cont.

\begin{tabular}{|c|c|c|c|c|c|c|}
\hline Tool Name & Type & Tool Features & Year & Authors & Journal/URL & $\begin{array}{l}\text { Reference } \\
\text { (DOI Number) }\end{array}$ \\
\hline MIRPIPE & Web & $\begin{array}{l}\text { - } \quad \text { Rapid and simple browser-based miRNA } \\
\text { homology detection and quantification of } \\
\text { miRNAs. } \\
\text { Read counts from isomiRs of the same miRNA } \\
\text { are combined. } \\
\text { - } \quad \text { Using FASTX-tollkit, Cutadapt, BLASTN. }\end{array}$ & 2014 & Carsten Kuenne et al. & $\begin{array}{l}\text { Bioinformatics } \\
\text { https:/ / www.ncbi.nlm. } \\
\text { nih.gov/pmc/articles/ } \\
\text { PMC4816158/ }\end{array}$ & $\begin{array}{l}\text { 10.1093/bioinformatics/btu573 } \\
\text { [86] }\end{array}$ \\
\hline CASMIR & $\begin{array}{l}\text { Standalone, } \\
\text { Linux }\end{array}$ & $\begin{array}{l}\text { - } \quad \text { Sequence-oriented isomiR annotation which } \\
\text { allows unbiased identification of global isomiRs } \\
\text { from small sequencing data. } \\
\text { Alignment against canonical and precursors } \\
\text { from miRBase. } \\
\text { Discovering of canonical, } 5^{\prime}, 3^{\prime}, \text { polymorphic, } \\
\text { mixed type, non-templated isomiRs, } \\
\text { quantification using miRDeep2. } \\
\text { - } \quad \text { In-house trimming and size filtering. } \\
\text { BLAST with in-house custom isomiR-BLAST } \\
\text { alignment tool. } \\
\text { Differential expression performed with a Poisson } \\
\text { regression model combined with a } \\
\text { quasi-likelihood approach and AUC based on } \\
\text { methods of DeLong and Clarke-Pearson. }\end{array}$ & 2018 & Chung Wah Wu et al. & $\begin{array}{l}\text { BMC Genomics } \\
\text { Open Access } \\
\text { https: } \\
\text { //www.ncbi.nlm.nih. } \\
\text { gov/pubmed/29801434 }\end{array}$ & $\begin{array}{l}10.1186 / \mathrm{s} 12864-018-4794-7 \\
{[87]}\end{array}$ \\
\hline IsomiR-SEA & $\begin{array}{l}\text { Linux } \\
\text { Windows } \\
\text { Mac }\end{array}$ & $\begin{array}{l}\text { - Provide users with a complete and accurate } \\
\text { picture of the miRNAs, isomiRs and conserved } \\
\text { miRNA:mRNA interaction sites. } \\
\text { Provide accurate miRNA and isomiRs } \\
\text { expression levels. } \\
\text { - } \quad \text { Use a specialized algorithm for alignment. } \\
\text { Evaluates the positions of the encountered } \\
\text { mismatches in analyzed tags. }\end{array}$ & 2016 & Gianvito Urgese et al. & $\begin{array}{l}\text { BMC Bioinformatics } \\
\text { https: } \\
\text { //bmcbioinformatics. } \\
\text { biomedcentral.com/ } \\
\text { articles/10.1186/s12859 } \\
\text {-016-0958-0 }\end{array}$ & $\begin{array}{l}10.1186 / \mathrm{s} 12859-016-0958-0 \\
{[88]}\end{array}$ \\
\hline
\end{tabular}


Table 1. Cont.

\begin{tabular}{|c|c|c|c|c|c|c|}
\hline Tool Name & Type & Tool Features & Year & Authors & Journal/URL & $\begin{array}{l}\text { Reference } \\
\text { (DOI Number) }\end{array}$ \\
\hline DeAnnIso & Web & $\begin{array}{l}\text { - } \quad \text { Detection and annotation of IsomiRs from sRNA } \\
\text { - } \quad \text { Extract the differentially expressing isomiRs with } \\
\text { isomiRs expression, isomiRs classification from } \\
\text { paired or multiple samples. } \\
\text { - } \quad \text { Tissue specific isomiR expression. } \\
\text { - } \quad \text { Noring Bowtie and BLAST with miRBase. } \\
\text { - } \quad \text { isomiRs' classification, } 5^{\prime} \text { isomiRs, } 3 \text { isomiRs, } \\
\text { isomiRs with internal modifications, templated } \\
\text { and non-templated. } \\
\text { Target analysis and enrichment analysis of } \\
\text { isomiRs with miRanda or RNA hybrid. }\end{array}$ & 2016 & Yuanwei Zhang et al. & $\begin{array}{l}\text { Nucleic Acids Research } \\
\text { https: } \\
\text { //www.ncbi.nlm.nih. } \\
\text { gov/pubmed/27179030 }\end{array}$ & 10.1093/nar/gkw427 [89] \\
\hline IsomiRage & $\begin{array}{l}\text { Windows } \\
\text { Mac }\end{array}$ & $\begin{array}{l}\text { Identification of miRNA variants (canonical } \\
\text { miRNAs, templated and non-templated isomiRs). } \\
\text { Detects and groups all } 3^{\prime}-5^{\prime}-\text { and } \\
\text { trimmed variants. } \\
\text { - } \quad \text { Uses reference sequences from miRBase. } \\
\text { Classification of isomiRs according to the type of } \\
\text { modification (uridylation, adenylation, etc.). } \\
\text { Mapping performed with Bowtie with no } \\
\text { mismatches to reference and custom genome. } \\
\text { Normalization with RPM and read counts that } \\
\text { can be used for comparisons of fold changes and } \\
\text { other downstream analyses. }\end{array}$ & 2014 & Muller Heiko et al. & $\begin{array}{l}\text { Frontiers in } \\
\text { Bioengineering and } \\
\text { Biotechnology } \\
\text { https: } \\
\text { //www.frontiersin.org/ } \\
\text { articles/10.3389/fbioe. } \\
\text { 2014.00038/full }\end{array}$ & $\begin{array}{l}\text { 10.3389/fbioe. } 2014.00038 \\
{[90]}\end{array}$ \\
\hline QuagmiR & $\begin{array}{l}\text { Standalone, } \\
\text { Web }\end{array}$ & $\begin{array}{l}\text { Designed for the detection and annotation of } \\
\text { heterogeneous isomiRs. } \\
\text { Provide extensive customization of the process } \\
\text { and reference databases according to user's } \\
\text { diverse research needs. } \\
\text { Can be used to analyze both private datasets and } \\
\text { the public datasets that are available to } \\
\text { authorized researchers through the CGC. }\end{array}$ & 2018 & Xavier Bofill-De Ros et al. & $\begin{array}{l}\text { Bioimformatics } \\
\text { https:/ / www.ncbi.nlm. } \\
\text { nih.gov / pmc/articles / } \\
\text { PMC6499244/ }\end{array}$ & $\begin{array}{l}\text { 10.1093/bioinformatics/bty } 843 \\
\text { [91] }\end{array}$ \\
\hline
\end{tabular}


Table 1. Cont.

\begin{tabular}{|c|c|c|c|c|c|c|}
\hline Tool Name & Type & Tool Features & Year & Authors & Journal/URL & $\begin{array}{l}\text { Reference } \\
\text { (DOI Number) }\end{array}$ \\
\hline Jasmine & R + Java & $\begin{array}{l}\text { - } \quad \text { Identification of isomiR populations. } \\
\text { - } \quad \text { Propose a comprehensive isomiR nomenclature. } \\
\text { - } \quad \text { Adapter trimming (trimmomatic, cutadapt). } \\
\text { - Collapsing trimmed reads (fastx_collapser, } \\
\text { fastq_to_fasta from FASTX-toolkit), } \\
\text { - } \text { quality control (FastQC). } \\
\text { - } \quad \text { Uses ming with Bowtie with at least one mismatch. } \\
\text { - }\end{array}$ & 2019 & Xiangfu Zhong et al. & $\begin{array}{l}\text { Bioinformatics } \\
\text { https://academic.oup. } \\
\text { com/bioinformatics/ } \\
\text { advance-article/doi/10 } \\
.1093 / \text { bioinformatics/ } \\
\text { btz806/5612093 }\end{array}$ & $\begin{array}{l}\text { 10.1093/bioinformatics/btz806 } \\
\text { [92] }\end{array}$ \\
\hline CBS-miRSeq & $\begin{array}{l}\text { Linux, } \\
\text { Docker } \\
\text { VM }\end{array}$ & $\begin{array}{ll}\text { - } & \text { Color-spaced raw reads. } \\
\text { Read length distribution, summary of adapter } \\
\text { removal, mapping statistics, and raw expression } \\
\text { - } \quad \text { Using Bowtie with reference genome. } \\
\text { - } \quad \text { Differential expression analysis using } \\
\text { DESeq2, EdgeR. } \\
\text { - } \quad \text { Identifies isomiRs using miRspring. } \\
\text { Predicts novel miRNA candidates } \\
\text { - } \quad \text { Pring miRDeep2. } \\
\quad \text { Predicts the most consistent miRNA:mRNA } \\
\text { unique pairs, using RNAhybrid, miRanda. }\end{array}$ & 2019 & Rupesh K. Kesharwani et al. & $\begin{array}{l}\text { Computers in Biology } \\
\text { and Medicine } \\
\text { https: } \\
\text { //www.sciencedirect. } \\
\text { com/science/article/ } \\
\text { pii/S001048251930188X }\end{array}$ & $\begin{array}{l}\text { 10.1016/j.compbiomed.2019.05.019. } \\
\text { [93] }\end{array}$ \\
\hline sRNAtoolbox & Web & 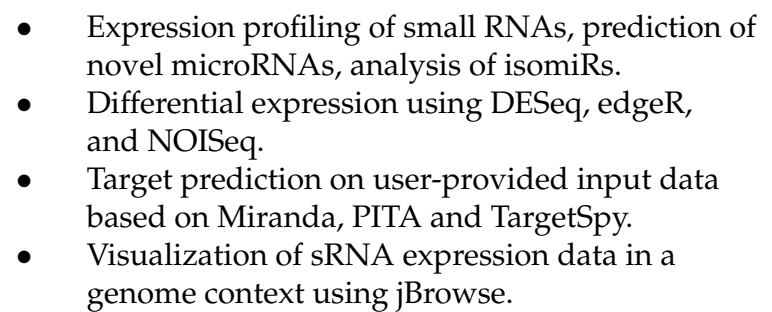 & 2015 & Antonio Rueda et al. & $\begin{array}{l}\text { Nucleic Acids Research } \\
\text { https:// www.ncbi.nlm. } \\
\text { nih.gov/pmc/articles/ } \\
\text { PMC4489306/pdf/gkv5 } \\
\text { 55.pdf }\end{array}$ & $\begin{array}{l}\text { 10.1093/nar/gkv555 } \\
{[94]}\end{array}$ \\
\hline
\end{tabular}


Table 1. Cont.

\begin{tabular}{|c|c|c|c|c|c|c|}
\hline Tool Name & Type & Tool Features & Year & Authors & Journal/URL & $\begin{array}{l}\text { Reference } \\
\text { (DOI Number) }\end{array}$ \\
\hline sRNAnalyzer & Web & $\begin{array}{l}\text { - } \quad \text { MiRNA profiling strategies for isomiRs. } \\
\text { - } \quad \text { Detection of potential SNPs in miRNAs. } \\
\text { and Cutadapt, Printseq, FastX for preprocessing } \\
\text { MirGen DB. } \\
\text { - } \quad \text { Use of LPM (local probability mapping) strategy } \\
\text { to increase mapping specificity. } \\
\text { - } \quad \text { Extensive rRNA and tRNA filtering steps to } \\
\text { enhance the accuracy of exogenous } \\
\text { RNA mapping. } \\
\text { Exogenous RNA mapping process } \\
\text { using sRNAnalyzer. }\end{array}$ & 2017 & Xiaogang Wu et al. & $\begin{array}{l}\text { Nucleic Acids Research } \\
\text { Open Access } \\
\text { https: } \\
\text { //www.ncbi.nlm.nih. } \\
\text { gov/pubmed/29069500 }\end{array}$ & $\begin{array}{l}\text { 10.1093/nar/gkx999 } \\
\text { [95] }\end{array}$ \\
\hline mirPRo & Linux & $\begin{array}{l}\text { - } \quad \text { Quantify known miRNAs. } \\
\text { Predict novel miRNAs and miRNA family } \\
\text { - } \quad \text { Ispression quantification. } \\
\text { - } \quad \text { Arm switching detection. } \\
\text { - } \quad \text { Using Novoalign, HTSeq, and pre-miRNAs } \\
\text { from miRBase. } \\
\text { - Using DESeq to perform differential expression } \\
\text { profile analysis for known and novel } \\
\text { mature miRNAs. }\end{array}$ & 2015 & Jieming Shi et al. & $\begin{array}{l}\text { Scientific Reports } \\
\text { Open Access } \\
\text { https:/ / www.ncbi.nlm. } \\
\text { nih.gov/pmc/articles / } \\
\text { PMC4592965/ }\end{array}$ & $\begin{array}{l}\text { 10.1038/srep14617 } \\
{[96]}\end{array}$ \\
\hline miRge & Standalone & $\begin{array}{l}\text { - } \quad \text { MirGeneDB miRNAs were used to assemble } \\
\text { positive clusters (known miRNAs and tRNA, } \\
\text { snoRNA, rRNA or mRNA were used to assemble } \\
\text { negative clusters (known non-miRNAs). } \\
\text { - } \quad \text { Identification of isomiRs. } \\
\text { - } \quad \text { Novel miRNA detection. } \\
\text { Preprocessing with Cutadapt and } \\
\text { mapping (Bowtie). } \\
\text { - } \quad \text { Using miRbase and miRGen DB. } \\
\text { Detection of A-to-I editing. }\end{array}$ & 2015 & Alexander S. Baras et al. & $\begin{array}{l}\text { Plos one } \\
\text { Open Access } \\
\text { https://journals.plos. } \\
\text { org/plosone/article?id= } \\
\text { 10.1371/journal.pone. } 01 \\
43066\end{array}$ & $\begin{array}{l}\text { 10.1371/journal.pone. } 0143066 \\
\text { [97] }\end{array}$ \\
\hline
\end{tabular}


Table 1. Cont

\begin{tabular}{|c|c|c|c|c|c|c|}
\hline Tool Name & Type & Tool Features & Year & Authors & Journal/URL & $\begin{array}{l}\text { Reference } \\
\text { (DOI Number) }\end{array}$ \\
\hline miRDis & Web & 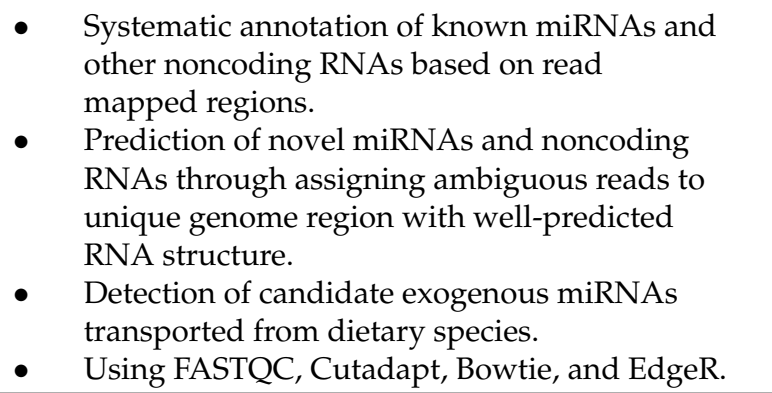 & 2017 & Hanyuan Zhang et al. & $\begin{array}{l}\text { Briefings in } \\
\text { Bioinformatics } \\
\text { Open Access } \\
\text { https: } \\
\text { //www.ncbi.nlm.nih. } \\
\text { gov/pubmed/28073746 }\end{array}$ & 10.1093/bib/bbw140 [98] \\
\hline miRMOD & Windows & $\begin{array}{l}\text { - Identifies and analyzes miRNA } 3^{\prime} \text { and } 5^{\prime} \\
\text { modifications (non-templated additions as well } \\
\text { as trimming). } \\
\text { - Using Bowtie with reference } \\
\text { genome/pre-miRNA. } \\
\text { - Provides useful statistics about various types of } \\
\text { miRNA modifications along with its frequencies. } \\
\text { - Target alteration analysis. }\end{array}$ & 2015 & Abhinav Kaushik et al. & $\begin{array}{l}\text { PeerJ } \\
\text { Open Access } \\
\text { https: } \\
\text { //www.ncbi.nlm.nih. } \\
\text { gov/pubmed/26623179 }\end{array}$ & $\begin{array}{l}\text { 10.7717/peerj.1332 } \\
\text { [99] }\end{array}$ \\
\hline mirTools 2.0 & Web & $\begin{array}{l}\text { - } \quad \text { Detection of various types of ncRNAs (miRNA, } \\
\text { tRNA, snRNA, snoRNA, rRNA, and piRNA). } \\
\text { - } \quad \text { Identify miRNA-targeted genes. } \\
\text { Performs functional annotation or miRNA } \\
\text { targets (GO, KEGG, PPI). } \\
\text { Detect differentially expressed ncRNAs with } \\
\text { RPM and the Bayesian method. } \\
\text { - } \quad \text { Detect novel miRNAs using miRDeep. }\end{array}$ & 2013 & Jinyu Wu et al. & $\begin{array}{l}\text { RNA Biology } \\
\text { https://www.ncbi.nlm. } \\
\text { nih.gov/pmc/articles/ } \\
\text { PMC3849156/ }\end{array}$ & $\begin{array}{l}\text { 10.4161/rna.25193 } \\
{[100]}\end{array}$ \\
\hline
\end{tabular}


Table 1. Cont.

\begin{tabular}{|c|c|c|c|c|c|c|}
\hline Tool Name & Type & Tool Features & Year & Authors & Journal/URL & $\begin{array}{l}\text { Reference } \\
\text { (DOI Number) }\end{array}$ \\
\hline Chimira & Web & $\begin{array}{l}\text { - Sequences are automatically cleaned, trimmed, } \\
\text { size-selected, and mapped directly to miRNA } \\
\text { hairpin sequences. } \\
\text { Identifies epi-transcriptomic modifications in the } \\
\text { input sequences. } \\
\text { Alignment with BLAST to miRbase and } \\
\text { differential expression of miRNAs using DESeq2. } \\
\text { Modification profiles of } 3^{\prime} \text { and } 5^{\prime} \text { and internal } \\
\text { modifications, uridylation, adenylation, } \\
\text { and internal modifications or variations of } \\
\text { the miRNAs. }\end{array}$ & 2015 & Dimitrios M. Vitsios et al. & $\begin{array}{l}\text { Bioinformatics } \\
\text { https:// www.ncbi.nlm. } \\
\text { nih.gov/pmc/articles/ } \\
\text { PMC4595902/ }\end{array}$ & $\begin{array}{l}\text { 10.1093/bioinformatics/btv380 } \\
\text { [101] }\end{array}$ \\
\hline miRTOP & $\begin{array}{l}\text { Standalone, } \\
\text { Linux }\end{array}$ & $\begin{array}{l}\text { - } \quad \text { Generation of a new file format mirGFF3. } \\
\text { output files (sRNAbench, Prost!, isomiR-SEA, } \\
\text { and OptimiR, e.g.,). } \\
\text { - } \quad \text { Converts mirGFF3 file into several different types } \\
\text { such as count matrix, FASTA, and VCF formats. } \\
\text { - } \quad \text { Open source and community-based project. } \\
\text { API for the standardization of miRNA and } \\
\text { isomiR annotation, enabling data } \\
\text { sharing, reporting. }\end{array}$ & 2019 & Thomas Desvignes et al. & $\begin{array}{l}\text { Bioinformatics } \\
\text { Open Access } \\
\text { https: } \\
\text { //academic.oup.com/ } \\
\text { bioinformatics/article/ } \\
\text { 36/3/698/5556118 }\end{array}$ & $\begin{array}{l}\text { 10.1093/bioinformatics/btz675 } \\
\text { [102] }\end{array}$ \\
\hline Prost! & $\begin{array}{l}\text { Standalone, } \\
\text { Linux }\end{array}$ & $\begin{array}{l}\text { - } \quad \text { Aligns reads to a user-defined genomic dataset. } \\
\text { - } \quad \text { roups reads based on their potential genomic } \\
\text { Reports frequencies of individual sequence } \\
\text { variations with respect to reference genome and } \\
\text { the most expressed sequence. } \\
\text { Uses Cutadapt and FASTX-toolkit for } \\
\text { preprocessing, BBMap suite for alignment, } \\
\text { miRBase for annotation, and DESeq2 for } \\
\text { differential expression. }\end{array}$ & 2019 & Thomas Desvignes et al. & $\begin{array}{l}\text { Scientific Reports } \\
\text { Open Access } \\
\text { https:/ / www.nature. } \\
\text { com/articles / s41598-0 } \\
\text { 19-40361-8 }\end{array}$ & $10.1038 / \mathrm{s} 41598-019-40361-8$ [103] \\
\hline
\end{tabular}


Table 1. Cont

\begin{tabular}{|c|c|c|c|c|c|c|}
\hline Tool Name & Type & Tool Features & Year & Authors & Journal/URL & $\begin{array}{l}\text { Reference } \\
\text { (DOI Number) }\end{array}$ \\
\hline OptimiR & $\begin{array}{l}\text { Standalone, } \\
\text { Linux }\end{array}$ & $\begin{array}{l}\text { - Incorporates biological knowledge on miRNA } \\
\text { editing and genome-wide genotype data } \\
\text { Novel miRNAs and highlighting the allelic } \\
\text { imbalance expression of polymiRs in } \\
\text { heterozygous carriers. } \\
\text { - Uses Cutadapt for preprocessing, Bowtie2 for } \\
\text { alignment, and miRBase for annotation. } \\
\text { - Uses a scoring algorithm to identify the most } \\
\text { plausible alignments. } \\
\text { Produces a comparison analysis of genotype data } \\
\text { provided by the user and the genotype data that } \\
\text { could be inferred from the sequenced reads } \\
\text { aligned to polymiRs. }\end{array}$ & 2019 & Florian Thibord et al. & $\begin{array}{l}\text { RNA } \\
\text { Open Access } \\
\text { https: } \\
\text { //rnajournal.cshlp.org/ } \\
\text { content/early/2019/02/ } \\
\text { 28/rna.069708.118 }\end{array}$ & $\begin{array}{l}\text { 10.1261/rna. } \\
\text { 069708.118. [104] }\end{array}$ \\
\hline isomiRs & R library & $\begin{array}{l}\text { - Uses as input file the count matrix. } \\
\text { Includes various functions for characterization of } \\
\text { miRNAs and isomiRs, clustering, differential } \\
\text { expression, and visualizations. } \\
\text { Designed to analyze the output of SeqBuster tool } \\
\text { or any other tool after converting to the } \\
\text { desire format [105]. }\end{array}$ & 2020 & Pantano L., Escaramis G. & $\begin{array}{l}\text { http: } \\
\text { //bioconductor.org/ } \\
\text { packages/release/bioc/ } \\
\text { html/isomiRs.html }\end{array}$ & 10.18129/B9.bioc.isomiRs \\
\hline
\end{tabular}




\section{IsomiRs-A Limitless Source of Potentially Novel Biomarkers}

Apart from the well-documented association of mature (e.g., RefSeq) miRNAs with diverse human diseases, recent evidence also supports dynamic isomiR repertoire in a variety of normal and diseased (pathological) tissues. Specific isomiR expression patterns have been attributed to different normal tissue types and found dependent on the tissue state, population origin, individual's gender, and race [36,39,40,106].

IsomiRs have been associated with several human diseases such as pre-eclampsia [106], Huntington disease [107], Alzheimer's disease [108], osteoarthritis [109], cardiovascular diseases [110], rheumatoid arthritis [111], and found to respond to bacterial infection [112]. Specific isomiR expression patterns have been observed in various cancer types $[113,114]$ suggesting the miRNA-mediated level of regulation of tumorigenesis. In gastric cancer, several mature miRNAs generated from the two different arms ( $5 p$ or $3 p$ ) of the same premiRNA exhibit reversed expression preferences (normal vs. cancer tissue) [115]. Next to the differential "arm-switch" expression, the enrichment of specific isomiRs produced from the same precursor may also exhibit differential expression preferences [115]. IsomiRs can function in a synergistic network with related miRNAs to suppress tumor development and progression, as it was demonstrated for miR-140-3p and its isoform in breast cancer [73], miR-451a and its isomiRs in melanoma [116], and miR-139-5p isoforms in hepatocellular carcinoma [117].

The accumulated evidence shows that the analysis of isomiRs expression pattern can differentiate tumor cells from normal, and moreover to discriminate amongst different tumor types and subtypes $[118,119]$. This strongly suggests isomiRs as potentially valuable diagnostic and prognostic biomarkers in cancer diagnostics [119-121]. Furthermore, the combination of isomiR features with state-of-the-art algorithms effectively differentiated normal from cancer cell lines [118,122]. Mature miRNAs and their isomiR variants, along with their target pathways, should be considered during tumor diagnosis, progression and treatment monitoring [114].

Several studies on body fluids such as blood (plasma and serum), urine, sputum, cerebrospinal fluid, and milk have shown an abundance not only of numerous miRNAs but also of their isomiR variants [123]. Although many of them can be found in circulation [124], enrichment of miRNAs and their isomiRs can be found in blood analytes such as human platelets (e.g., cytoplasm fragments derived from bone marrow megakaryocytes) and extracellular vesicles (EVs, e.g., secreted membrane-enclosed particles that are released naturally from the cell) $[70,120,123,125]$. In addition, EVs isolated from the urine of prostate cancer patients showed enrichment in miRNAs and isomiRs with potential for biomarkers in minimally invasive diagnosis of prostate cancer patients [126]. The most common feature among biofluid studies is that isomiRs have a higher abundance than known miRNAs $[39,127,128]$. This suggests miRNA precursors may generate more than one miRNA variants with specific properties. New in-depth studies on miRNAs and isomiRs, including the exploitation of their biosources and intricate molecular properties, in combination with the state-of-the-art computational algorithms, will aid further exploration of this rich and versatile source of potentially new biomarkers.

Funding: This project has received funding from the European Union's Horizon 2020 research and innovation programme under the Marie Skłodowska-Curie grant agreement No 765492, and the National Science Fund of Bulgaria (КП-06 H31/2).

Acknowledgments: This project has received funding from the European Union's Horizon 2020 research and innovation programme under the Marie Skłodowska-Curie grant agreement No 765492, and the National Science Fund of Bulgaria (КП-06 H31/2).

Conflicts of Interest: T.W. is shareholder of GRAIL, Inc.; D.K.-L. is shareholder of ExBiome BV. 


\section{References}

1. Lee, R.C.; Feinbaum, R.L.; Ambros, V. The C. elegans heterochronic gene lin-4 encodes small RNAs with antisense complementarity to lin-14. Cell 1993, 75, 843-854. [CrossRef]

2. Wightman, B.; Ha, I.; Ruvkun, G. Posttranscriptional regulation of the heterochronic gene lin-14 by lin-4 mediates temporal pattern formation in C. elegans. Cell 1993, 75, 855-862. [CrossRef]

3. Kozomara, A.; Griffiths-Jones, S. MiRBase: Annotating high confidence microRNAs using deep sequencing data. Nucleic Acids Res. 2014, 42, 68-73. [CrossRef] [PubMed]

4. Kozomara, A.; Birgaoanu, M.; Griffiths-Jones, S. MiRBase: From microRNA sequences to function. Nucleic Acids Res. 2019, 47, D155-D162. [CrossRef] [PubMed]

5. Friedman, R.C.; Farh, K.K.H.; Burge, C.B.; Bartel, D.P. Most mammalian mRNAs are conserved targets of microRNAs. Genome Res. 2009, 19, 92-105. [CrossRef] [PubMed]

6. Lagos-Quintana, M.; Rauhut, R.; Lendeckel, W.; Tuschl, T. Identification of Novel Genes Coding for Small Expressed RNAs. Science 2001, 294, 853-858. [CrossRef]

7. Rodriguez, A.; Griffiths-Jones, S.; Ashurst, J.L.; Bradley, A. Identification of mammalian microRNA host genes and transcription units. Genome Res. 2004, 14, 1902-1910. [CrossRef]

8. Lee, Y.; Jeon, K.; Lee, J.T.; Kim, S.; Kim, V.N. MicroRNA maturation: Stepwise processing and subcellular localization. EMBO J. 2002, 21, 4663-4670. [CrossRef]

9. Lee, Y.; Kim, M.; Han, J.; Yeom, K.H.; Lee, S.; Baek, S.H.; Kim, V.N. MicroRNA genes are transcribed by RNA polymerase II. EMBO J. 2004, 23, 4051-4060. [CrossRef]

10. Jones-Rhoades, M.W.; Bartel, D.P.; Bartel, B. MicroRNAs and their regulatory roles in plants. Annu. Rev. Plant Biol. 2006, 57, 19-53. [CrossRef]

11. Gregory, R.I.; Yan, K.P.; Amuthan, G.; Chendrimada, T.; Doratotaj, B.; Cooch, N.; Shiekhattar, R. The Microprocessor complex mediates the genesis of microRNAs. Nature 2004, 432, 235-240. [CrossRef] [PubMed]

12. Lund, E.; Güttinger, S.; Calado, A.; Dahlberg, J.E.; Kutay, U. Nuclear Export of MicroRNA Precursors. Science 2004, 303, 95-98. [CrossRef] [PubMed]

13. Yi, R.; Qin, Y.; Macara, I.G.; Cullen, B.R. Exportin-5 mediates the nuclear export of pre-microRNAs and short hairpin RNAs. Genes Dev. 2003, 17, 3011-3016. [CrossRef] [PubMed]

14. Bohnsack, M.T.; Czaplinski, K.; Görlich, D. Exportin 5 is a RanGTP-dependent dsRNA-binding protein that mediates nuclear export of pre-miRNAs. RNA 2004, 10, 185-191. [CrossRef]

15. Rna, S.T.; Hutvágner, G.; Mclachlan, J.; Pasquinelli, A.E.; Bálint, É.; Zamore, P.D.; Rock, K.; Hutvagner, G.; Mclachlan, J.; Pasquinelli, A.E.; et al. A cellular function for the RNA-interference enzyme Dicer in the maturation of the let-7 small temporal RNA. Science 2001, 293, 834-838.

16. Lee, Y.; Hur, I.; Park, S.Y.; Kim, Y.K.; Mi, R.S.; Kim, V.N. The role of PACT in the RNA silencing pathway. EMBO J. 2006, 25, 522-532. [CrossRef]

17. Lee, H.Y.; Zhou, K.; Smith, A.M.; Noland, C.L.; Doudna, J.A. Differential roles of human Dicer-binding proteins TRBP and PACT in small RNA processing. Nucleic Acids Res. 2013, 41, 6568-6576. [CrossRef]

18. Lee, Y.; Ahn, C.; Han, J.; Choi, H.; Kim, J.; Yim, J.; Lee, J.; Provost, P.; Rådmark, O.; Kim, S.; et al. The nuclear RNase III Drosha initiates microRNA processing. Nature 2003, 425, 415-419. [CrossRef]

19. Zhang, H.; Kolb, F.A.; Jaskiewicz, L.; Westhof, E.; Filipowicz, W. Single processing center models for human Dicer and bacterial RNase III. Cell 2004, 118, 57-68. [CrossRef]

20. Du, T.; Zamore, P.D. microPrimer: The biogenesis and function of microRNA. Development 2005, 132, 4645-4652. [CrossRef]

21. Khvorova, A.; Reynolds, A.; Jayasena, S.D. Erratum: Functional siRNAs and miRNAs Exhibit Strand Bias (Cell 115 (209-216)). Cell 2003, 115, 505. [CrossRef]

22. Schwarz, D.S.; Hutvágner, G.; Du, T.; Xu, Z.; Aronin, N.; Zamore, P.D. Asymmetry in the assembly of the RNAi enzyme complex. Cell 2003, 115, 199-208. [CrossRef]

23. Frank, F.; Sonenberg, N.; Nagar, B. Structural basis for 5'-nucleotide base-specific recognition of guide RNA by human AGO2. Nature 2010, 465, 818-822. [CrossRef] [PubMed]

24. Suzuki, H.I.; Katsura, A.; Yasuda, T.; Ueno, T.; Mano, H.; Sugimoto, K.; Miyazono, K. Small-RNA asymmetry is directly driven by mammalian Argonautes. Nat. Struct. Mol. Biol. 2015, 22, 512-521. [CrossRef] [PubMed]

25. Liu, J.; Carmell, M.A.; Rivas, F.V.; Marsden, C.G.; Thomson, J.M.; Song, J.J.; Hammond, S.M.; Joshua-Tor, L.; Hannon, G.J. Argonaute2 is the catalytic engine of mammalian RNAi. Science 2004, 305, 1437-1441. [CrossRef]

26. Reichholf, B.; Herzog, V.A.; Fasching, N.; Manzenreither, R.A.; Sowemimo, I.; Ameres, S.L. Time-Resolved Small RNA Sequencing Unravels the Molecular Principles of MicroRNA Homeostasis. Mol. Cell 2019, 75, 756-768.e7. [CrossRef]

27. Yang, J.S.; Maurin, T.; Lai, E.C. Functional parameters of Dicer-independent microRNA biogenesis. RNA 2012, 18, 945-957. [CrossRef]

28. Cheloufi, S.; Dos Santos, C.O.; Chong, M.M.W.; Hannon, G.J. A dicer-independent miRNA biogenesis pathway that requires Ago catalysis. Nature 2010, 465, 584-589. [CrossRef] 
29. Cifuentes, D.; Xue, H.; Taylor, D.W.; Patnode, H.; Mishima, Y.; Cheloufi, S.; Ma, E.; Mane, S.; Hannon, G.J.; Lawson, N.D.; et al. A novel miRNA processing pathway independent of dicer requires argonaute2 catalytic activity. Science 2010, 328, 1694-1698. [CrossRef]

30. Okamura, K.; Hagen, J.W.; Duan, H.; Tyler, D.M.; Lai, E.C. The Mirtron Pathway Generates microRNA-Class Regulatory RNAs in Drosophila. Cell 2007, 130, 89-100. [CrossRef]

31. Ruby, J.G.; Jan, C.H.; Bartel, D.P. Intronic microRNA precursors that bypass Drosha processing. Nature 2007, 448, 83-86. [CrossRef] [PubMed]

32. Berezikov, E.; Chung, W.J.; Willis, J.; Cuppen, E.; Lai, E.C. Mammalian Mirtron Genes. Mol. Cell 2007, 28, 328-336. [CrossRef] [PubMed]

33. Morin, R.D.; O'Connor, M.D.; Griffith, M.; Kuchenbauer, F.; Delaney, A.; Prabhu, A.L.; Zhao, Y.; McDonald, H.; Zeng, T.; Hirst, M.; et al. Application of massively parallel sequencing to microRNA profiling and discovery in human embryonic stem cells. Genome Res. 2008, 18, 610-621. [CrossRef] [PubMed]

34. Burroughs, A.M.; Ando, Y.; de Hoon, M.L.; Tomaru, Y.; Suzuki, H.; Hayashizaki, Y.; Daub, C.O. Deep-sequencing of human Argonaute-associated small RNAs provides insight into miRNA sorting and reveals Argonaute association with RNA fragments of diverse origin. RNA Biol. 2011, 8, 158-177. [CrossRef]

35. Neilsen, C.T.; Goodall, G.J.; Bracken, C.P. IsomiRs-The overlooked repertoire in the dynamic microRNAome. Trends Genet. 2012, 28, 544-549. [CrossRef]

36. Tan, G.C.; Chan, E.; Molnar, A.; Sarkar, R.; Alexieva, D.; Isa, I.M.; Robinson, S.; Zhang, S.; Ellis, P.; Langford, C.F.; et al. 5' isomiR variation is of functional and evolutionary importance. Nucleic Acids Res. 2014, 42, 9424-9435. [CrossRef]

37. Desvignes, T.; Batzel, P.; Berezikov, E.; Eilbeck, K.; Eppig, J.T.; McAndrews, M.S.; Singer, A.; Postlethwait, J.H. MiRNA Nomenclature: A View Incorporating Genetic Origins, Biosynthetic Pathways, and Sequence Variants. Trends Genet. 2015, 31, 613-626. [CrossRef]

38. Kozomara, A.; Griffiths-Jones, S. MiRBase: Integrating microRNA annotation and deep-sequencing data. Nucleic Acids Res. 2011, 39, 1-6. [CrossRef]

39. Loher, P.; Londin, E.R.; Rigoutsos, I. IsomiR expression profiles in human lymphoblastoid cell lines exhibit population and gender dependencies. Oncotarget 2014, 5, 8790-8802. [CrossRef]

40. Telonis, A.G.; Loher, P.; Jing, Y.; Londin, E.; Rigoutsos, I. Beyond the one-locus-one-miRNA paradigm: microRNA isoforms enable deeper insights into breast cancer heterogeneity. Nucleic Acids Res. 2015, 43, 9158-9175. [CrossRef]

41. Zeng, Y.; Yi, R.; Cullen, B.R. Recognition and cleavage of primary microRNA precursors by the nuclear processing enzyme Drosha. EMBO J. 2005, 24, 138-148. [CrossRef] [PubMed]

42. Park, J.E.; Heo, I.; Tian, Y.; Simanshu, D.K.; Chang, H.; Jee, D.; Patel, D.J.; Kim, V.N. Dicer recognizes the $5^{\prime}$ end of RNA for efficient and accurate processing. Nature 2011, 475, 201-205. [CrossRef] [PubMed]

43. Wu, H.; Ye, C.; Ramirez, D.; Manjunath, N. Alternative processing of primary microRNA transcripts by Drosha generates $5^{\prime}$ end variation of mature microRNA. PLoS ONE 2009, 4. [CrossRef] [PubMed]

44. Kim, B.; Jeong, K.; Kim, V.N. Genome-wide Mapping of DROSHA Cleavage Sites on Primary MicroRNAs and Noncanonical Substrates. Mol. Cell 2017, 66, 258-269.e5. [CrossRef]

45. Wyman, S.K.; Knouf, E.C.; Parkin, R.K.; Fritz, B.R.; Lin, D.W.; Dennis, L.M.; Krouse, M.A.; Webster, P.J.; Tewari, M. Post-transcriptional generation of miRNA variants by multiple nucleotidyl transferases contributes to miRNA transcriptome complexity. Genome Res. 2011, 21, 1450-1461. [CrossRef]

46. Katoh, T.; Sakaguchi, Y.; Miyauchi, K.; Suzuki, T.; Suzuki, T.; Kashiwabara, S.I.; Baba, T. Selective stabilization of mammalian microRNAs by $3^{\prime}$ adenylation mediated by the cytoplasmic poly(A) polymerase GLD-2. Genes Dev. 2009, 23, 433-438. [CrossRef]

47. Burroughs, A.M.; Ando, Y.; De Hoon, M.J.L.; Tomaru, Y.; Nishibu, T.; Ukekawa, R.; Funakoshi, T.; Kurokawa, T.; Suzuki, H.; Hayashizaki, Y.; et al. A comprehensive survey of $3^{\prime}$ animal miRNA modification events and a possible role for $3^{\prime}$ adenylation in modulating miRNA targeting effectiveness. Genome Res. 2010, 20, 1398-1410. [CrossRef]

48. Boele, J.; Persson, H.; Shin, J.W.; Ishizu, Y.; Newie, I.S.; Søkilde, R.; Hawkins, S.M.; Coarfa, C.; Ikeda, K.; Takayama, K.I.; et al. PAPD5-mediated $3^{\prime}$ adenylation and subsequent degradation of miR-21 is disrupted in proliferative disease. Proc. Natl. Acad. Sci. USA 2014, 111, 11467-11472. [CrossRef]

49. Katoh, T.; Hojo, H.; Suzuki, T. Destabilization of microRNAs in human cells by $3^{\prime}$ deadenylation mediated by PARN and CUGBP1. Nucleic Acids Res. 2015, 43, 7521-7534. [CrossRef]

50. Heo, I.; Joo, C.; Kim, Y.K.; Ha, M.; Yoon, M.J.; Cho, J.; Yeom, K.H.; Han, J.; Kim, V.N. TUT4 in Concert with Lin28 Suppresses MicroRNA Biogenesis through Pre-MicroRNA Uridylation. Cell 2009, 138, 696-708. [CrossRef]

51. Hagan, J.P.; Piskounova, E.; Gregory, R.I. Lin28 recruits the TUTase Zcchc11 to inhibit let-7 maturation in mouse embryonic stem cells. Nat. Struct. Mol. Biol. 2009, 16, 1021-1025. [CrossRef] [PubMed]

52. Heo, I.; Ha, M.; Lim, J.; Yoon, M.J.; Park, J.E.; Kwon, S.C.; Chang, H.; Kim, V.N. Mono-uridylation of pre-microRNA as a key step in the biogenesis of group II let-7 microRNAs. Cell 2012, 151, 521-532. [CrossRef] [PubMed]

53. Thornton, J.E.; Du, P.; Jing, L.; Sjekloca, L.; Lin, S.; Grossi, E.; Sliz, P.; Zon, L.I.; Gregory, R.I. Selective microRNA uridylation by Zcchc6 (TUT7) and Zcchc11 (TUT4). Nucleic Acids Res. 2014, 42, 11777-11791. [CrossRef] [PubMed]

54. Yang, W.; Chendrimada, T.P.; Wang, Q.; Higuchi, M.; Seeburg, P.H.; Shiekhattar, R.; Nishikura, K. Modulation of microRNA processing and expression through RNA editing by ADAR deaminases. Nat. Struct. Mol. Biol. 2006, 13, 13-21. [CrossRef] 
55. Kawahara, Y.; Zinshteyn, B.; Sethupathy, P.; Iizasa, H.; Hatzigeorgiou, A.G.; Nishikura, K. Redirection of silencing targets by adenosine-to-inosine editing of miRNAs. Science 2007, 315, 1137-1140. [CrossRef]

56. Bass, B.L.; Weintraub, H. An unwinding activity that covalently modifies its double-stranded RNA substrate. Cell 1988, 55, 1089-1098. [CrossRef]

57. Kim, Y.; Kim, V.N. MicroRNA Factory: RISC Assembly from Precursor MicroRNAs. Mol. Cell 2012, 46, 384-386. [CrossRef]

58. Bernstein, E.; Caudy, A.A.; Hammond, S.M.; Hannon, G.J. Role for a bidentate ribonuclease in the initiation step of RNA interference. Nature 2001, 409, 363-366. [CrossRef]

59. Eulalio, A.; Behm-Ansmant, I.; Izaurralde, E. P bodies: At the crossroads of post-transcriptional pathways. Nat. Rev. Mol. Cell Biol. 2007, 8, 9-22. [CrossRef]

60. Lee, Y.S.; Dutta, A. MicroRNAs in Cancer. Annu. Rev. Pathol. Mech. Dis. 2009, 4, 199-227. [CrossRef]

61. Guo, H.; Ingolia, N.T.; Weissman, J.S.; Bartel, D.P. Mammalian microRNAs predominantly act to decrease target mRNA levels. Nature 2010, 466, 835-840. [CrossRef]

62. Huntzinger, E.; Izaurralde, E. Gene silencing by microRNAs: Contributions of translational repression and mRNA decay. Nat. Rev. Genet. 2011, 12, 99-110. [CrossRef]

63. Bukhari, S.I.A.; Truesdell, S.S.; Lee, S.; Kollu, S.; Classon, A.; Boukhali, M.; Jain, E.; Mortensen, R.D.; Yanagiya, A.; Sadreyev, R.I.; et al. A Specialized Mechanism of Translation Mediated by FXR1a-Associated MicroRNP in Cellular Quiescence. Mol. Cell 2016, 61, 760-773. [CrossRef] [PubMed]

64. Truesdell, S.S.; Mortensen, R.D.; Seo, M.; Schroeder, J.C.; Lee, J.H.; Letonqueze, O.; Vasudevan, S.V. MicroRNA-mediated mRNA translation activation in quiescent cells and oocytes involves recruitment of a nuclear microRNP. Sci. Rep. 2012, 2, 842. [CrossRef] [PubMed]

65. Vasudevan, S.; Tong, Y.; Steitz, J.A. Switching from Repression to Activation: MicroRNAs Can Up-Regulate Translation. Science 2007, 318, 1931-1934. [CrossRef] [PubMed]

66. Ørom, U.A.; Nielsen, F.C.; Lund, A.H. MicroRNA-10a Binds the 5'UTR of Ribosomal Protein mRNAs and Enhances Their Translation. Mol. Cell 2008, 30, 460-471. [CrossRef] [PubMed]

67. Fernandez-Valverde, S.L.; Taft, R.J.; Mattick, J.S. Dynamic isomiR regulation in Drosophila development. Rna 2010, 16, 1881-1888. [CrossRef] [PubMed]

68. Burns, D.M.; D'Ambrogio, A.; Nottrott, S.; Richter, J.D. CPEB and two poly(A) polymerases control miR-122 stability and p53 mRNA translation. Nature 2011,473, 105-108. [CrossRef] [PubMed]

69. Khudayberdiev, S.A.; Zampa, F.; Rajman, M.; Schratt, G. A comprehensive characterization of the nuclear microRNA repertoire of post-mitotic neurons. Front. Mol. Neurosci. 2013, 6, 1-19. [CrossRef]

70. Koppers-Lalic, D.; Hackenberg, M.; Bijnsdorp, I.V.; van Eijndhoven, M.A.J.; Sadek, P.; Sie, D.; Zini, N.; Middeldorp, J.M.; Ylstra, B.; de Menezes, R.X.; et al. Nontemplated nucleotide additions distinguish the small RNA composition in cells from exosomes. Cell Rep. 2014, 8, 1649-1658. [CrossRef]

71. Yamane, D.; Selitsky, S.R.; Shimakami, T.; Li, Y.; Zhou, M.; Honda, M.; Sethupathy, P.; Lemon, S.M. Differential hepatitis C virus RNA target site selection and host factor activities of naturally occurring miR-122 3' variants. Nucleic Acids Res. 2017, 45, 4743-4755. [CrossRef] [PubMed]

72. Humphreys, D.T.; Hynes, C.J.; Patel, H.R.; Wei, G.H.; Cannon, L.; Fatkin, D.; Suter, C.M.; Clancy, J.L.; Preiss, T. Complexity of murine cardiomyocyte miRNA biogenesis, sequence variant expression and function. PLoS ONE 2012, 7. [CrossRef] [PubMed]

73. Salem, O.; Erdem, N.; Jung, J.; Münstermann, E.; Wörner, A.; Wilhelm, H.; Wiemann, S.; Körner, C. The highly expressed 5'isomiR of hsa-miR-140-3p contributes to the tumor-suppressive effects of miR-140 by reducing breast cancer proliferation and migration. BMC Genom. 2016, 17, 566. [CrossRef] [PubMed]

74. Mercey, O.; Popa, A.; Cavard, A.; Paquet, A.; Chevalier, B.; Pons, N.; Magnone, V.; Zangari, J.; Brest, P.; Zaragosi, L.E.; et al. Characterizing isomiR variants within the microRNA-34/449 family. FEBS Lett. 2017, 591, 693-705. [CrossRef]

75. Landgraf, P.; Rusu, M.; Sheridan, R.; Sewer, A.; Iovino, N.; Aravin, A.; Pfeffer, S.; Rice, A.; Kamphorst, A.O.; Landthaler, M.; et al. A Mammalian microRNA Expression Atlas Based on Small RNA Library Sequencing. Cell 2007, 129, 1401-1414. [CrossRef]

76. Sdassi, N.; Silveri, L.; Laubier, J.; Tilly, G.; Costa, J.; Layani, S.; Vilotte, J.L.; Le Provost, F. Identification and characterization of new miRNAs cloned from normal mouse mammary gland. BMC Genom. 2009, 10, 149. [CrossRef]

77. Lee, L.W.; Zhang, S.; Etheridge, A.; Ma, L.; Martin, D.; Galas, D.; Wang, K. Complexity of the microRNA repertoire revealed by next-generation sequencing. RNA 2010, 16, 2170-2180. [CrossRef]

78. Cloonan, N.; Wani, S.; Xu, Q.; Gu, J.; Lea, K.; Heater, S.; Barbacioru, C.; Steptoe, A.L.; Martin, H.C.; Nourbakhsh, E.; et al. MicroRNAs and their isomiRs function cooperatively to target common biological pathways. Genome Biol. 2011, 12. [CrossRef]

79. Ziemann, M.; Kaspi, A.; El-Osta, A. Evaluation of microRNA alignment techniques. RNA 2016, 22, 1120-1138. [CrossRef]

80. Fehlmann, T.; Backes, C.; Kahraman, M.; Haas, J.; Ludwig, N.; Posch, A.E.; Würstle, M.L.; Hübenthal, M.; Franke, A.; Meder, B.; et al. Web-based NGS data analysis using miRMaster: A large-scale meta-analysis of human miRNAs. Nucleic Acids Res. 2017, 45, 8731-8744. [CrossRef]

81. Zhao, S.; Gordon, W.; Du, S.; Zhang, C.; He, W.; Xi, L.; Mathur, S.; Agostino, M.; Paradis, T.; von Schack, D.; et al. QuickMIRSeq: A pipeline for quick and accurate quantification of both known miRNAs and isomiRs by jointly processing multiple samples from microRNA sequencing. BMC Bioinform. 2017, 18. [CrossRef] [PubMed] 
82. Giurato, G.; De Filippo, M.R.; Rinaldi, A.; Hashim, A.; Nassa, G.; Ravo, M.; Rizzo, F.; Tarallo, R.; Weisz, A. iMir: An integrated pipeline for high-throughput analysis of small non-coding RNA data obtained by smallRNA-Seq. BMC Bioinform. 2013, 14, 362. [CrossRef] [PubMed]

83. Guo, L.; Yu, J.; Liang, T.; Zou, Q. MIR-isomiRExp: A web-server for the analysis of expression of miRNA at the miRNA/isomiR levels. Sci. Rep. 2016, 6, 23700. [CrossRef]

84. Aparicio, E.L.; Rueda, A.; Fromm, B.; Gómez-Martín, C.; Lebrón, R.; Oliver, J.L.; Marchal, J.A.; Kotsyfakis, M.; Hackenberg, M. MiRNAgFree: Prediction and profiling of novel microRNAs without genome assembly. bioRxiv 2017. [CrossRef]

85. De Oliveira, L.F.V.; Christoff, A.P.; Margis, R. isomiRID: A framework to identify microRNA isoforms. Bioinformatics 2013, 29, 2521-2523. [CrossRef]

86. Kuenne, C.; Preussner, J.; Herzog, M.; Braun, T.; Looso, M. MIRPIPE: Quantification of microRNAs in niche model organisms. Bioinformatics 2014, 30, 3412-3413. [CrossRef]

87. Wu, C.W.; Evans, J.M.; Huang, S.; Mahoney, D.W.; Dukek, B.A.; Taylor, W.R.; Yab, T.C.; Smyrk, T.C.; Jen, J.; Kisiel, J.B.; et al. A Comprehensive Approach to Sequence-oriented IsomiR annotation (CASMIR): Demonstration with IsomiR profiling in colorectal neoplasia. BMC Genom. 2018, 19. [CrossRef] [PubMed]

88. Urgese, G.; Paciello, G.; Acquaviva, A.; Ficarra, E. IsomiR-SEA: An RNA-Seq analysis tool for miRNAs/isomiRs expression level profiling and miRNA-mRNA interaction sites evaluation. BMC Bioinform. 2016, 17. [CrossRef] [PubMed]

89. Zhang, Y.; Zang, Q.; Zhang, H.; Ban, R.; Yang, Y.; Iqbal, F.; Li, A.; Shi, Q. DeAnnIso: A tool for online detection and annotation of isomiRs from small RNA sequencing data. Nucleic Acids Res. 2016, 44, W166-W175. [CrossRef] [PubMed]

90. Muller, H.; Marzi, M.J.; Nicassio, F. IsomiRage: From Functional Classification to Differential Expression of miRNA Isoforms. Front. Bioeng. Biotechnol. 2014, 2, 38. [CrossRef]

91. Bofill-De Ros, X.; Chen, K.; Chen, S.; Tesic, N.; Randjelovic, D.; Skundric, N.; Nesic, S.; Varjacic, V.; Williams, E.H.; Malhotra, R.; et al. QuagmiR: A cloud-based application for isomiR big data analytics. Bioinformatics 2019, 35, 1576-1578. [CrossRef] [PubMed]

92. Zhong, X.; Pla, A.; Rayner, S. Jasmine: A Java pipeline for isomiR characterization in miRNA-Seq data. Bioinformatics 2020, 36, 1933-1936. [CrossRef] [PubMed]

93. Kesharwani, R.K.; Chiesa, M.; Bellazzi, R.; Colombo, G.I. CBS-miRSeq: A comprehensive tool for accurate and extensive analyses of microRNA-sequencing data. Comput. Biol. Med. 2019, 110, 234-243. [CrossRef] [PubMed]

94. Rueda, A.; Barturen, G.; Lebrón, R.; Gómez-Martín, C.; Alganza, Á.; Oliver, J.L.; Hackenberg, M. SRNAtoolbox: An integrated collection of small RNA research tools. Nucleic Acids Res. 2015, 43, W467-W473. [CrossRef]

95. Wu, X.; Kim, T.K.; Baxter, D.; Scherler, K.; Gordon, A.; Fong, O.; Etheridge, A.; Galas, D.J.; Wang, K. SRNAnalyzer-A flexible and customizable small RNA sequencing data analysis pipeline. Nucleic Acids Res. 2017, 45, 12140-12151. [CrossRef]

96. Shi, J.; Dong, M.; Li, L.; Liu, L.; Luz-Madrigal, A.; Tsonis, P.A.; Del Rio-Tsonis, K.; Liang, C. MirPRo-a novel standalone program for differential expression and variation analysis of miRNAs. Sci. Rep. 2015, 5. [CrossRef]

97. Baras, A.S.; Mitchell, C.J.; Myers, J.R.; Gupta, S.; Weng, L.C.; Ashton, J.M.; Cornish, T.C.; Pandey, A.; Halushka, M.K. MiRge-A multiplexed method of processing small RNA-seq data to determine MicroRNA entropy. PLoS ONE 2015, 10, e0143066. [CrossRef]

98. Zhang, H.; e Silva, B.V.R.; Cui, J. miRDis: A Web tool for endogenous and exogenous microRNA discovery based on deepsequencing data analysis. Brief. Bioinform. 2018, 19, 415-424. [CrossRef]

99. Kaushik, A.; Saraf, S.; Mukherjee, S.K.; Gupta, D. miRMOD: A tool for identification and analysis of $5^{\prime}$ and $3^{\prime}$ miRNA modifications in Next Generation Sequencing small RNA data. PeerJ 2015, 2015. [CrossRef]

100. Wu, J.; Liu, Q.; Wang, X.; Zheng, J.; Wang, T.; You, M.; Sun, Z.S.; Shi, Q. MirTools 2.0 for non-coding RNA discovery, profiling and functional annotation based on high-throughput sequencing. RNA Biol. 2013, 10, 1087-1092. [CrossRef]

101. Vitsios, D.M.; Enright, A.J. Chimira: Analysis of small RNA sequencing data and microRNA modifications. Bioinformatics 2015, 31, 3365-3367. [CrossRef] [PubMed]

102. Desvignes, T.; Loher, P.; Eilbeck, K.; Ma, J.; Urgese, G.; Fromm, B.; Sydes, J.; Aparicio-Puerta, E.; Barrera, V.; Espín, R.; et al. Unification of miRNA and isomiR research: The mirGFF3 format and the mirtop API. bioRxiv 2018, 36, 698-703. [CrossRef] [PubMed]

103. Desvignes, T.; Batzel, P.; Sydes, J.; Eames, B.F.; Postlethwait, J.H. miRNA analysis with Prost! reveals evolutionary conservation of organ-enriched expression and post-transcriptional modifications in three-spined stickleback and zebrafish. Sci. Rep. 2019, 9, 3913. [CrossRef] [PubMed]

104. Thibord, F.; Perret, C.; Roux, M.; Suchon, P.; Germain, M.; Deleuze, J.F.; Morange, P.E.; Trégouët, D.A. OPTIMIR, a novel algorithm for integrating available genome-wide genotype data into miRNA sequence alignment analysis. RNA 2019, 25, 657-668. [CrossRef]

105. Pantano, L.; Estivill, X.; Martí, E. SeqBuster, a bioinformatic tool for the processing and analysis of small RNAs datasets, reveals ubiquitous miRNA modifications in human embryonic cells. Nucleic Acids Res. 2009, 38. [CrossRef]

106. Guo, L.; Liang, T.; Yu, J.; Zou, Q. A comprehensive analysis of miRNA/isomiR expression with gender difference. PLoS ONE 2016, 11, e0154955. [CrossRef]

107. Martí, E.; Pantano, L.; Bañez-Coronel, M.; Llorens, F.; Miñones-Moyano, E.; Porta, S.; Sumoy, L.; Ferrer, I.; Estivill, X. A myriad of miRNA variants in control and Huntington's disease brain regions detected by massively parallel sequencing. Nucleic Acids Res. 2010, 38, 7219-7235. [CrossRef] 
108. Wang, S.; Xu, Y.; Li, M.; Tu, J.; Lu, Z. Dysregulation of miRNA isoform level at $5^{\prime}$ end in Alzheimer's disease. Gene 2016, 584, 167-172. [CrossRef]

109. Haseeb, A.; Makki, M.S.; Khan, N.M.; Ahmad, I.; Haqqi, T.M. Deep sequencing and analyses of miRNAs, isomiRs and miRNA induced silencing complex (miRISC)-associated miRNome in primary human chondrocytes. Sci. Rep. 2017, 7, 15178. [CrossRef]

110. van der Kwast, R.V.C.T.; Woudenberg, T.; Quax, P.H.A.; Nossent, A.Y. MicroRNA-411 and Its 5'-IsomiR Have Distinct Targets and Functions and Are Differentially Regulated in the Vasculature under Ischemia. Mol. Ther. 2019, 28, 157-170. [CrossRef]

111. Ormseth, M.J.; Solus, J.F.; Sheng, Q.; Ye, F.; Wu, Q.; Guo, Y.; Oeser, A.M.; Allen, R.M.; Vickers, K.C.; Stein, C.M. Development and validation of a MicroRNA panel to differentiate between patients with rheumatoid arthritis or systemic lupus erythematosus and controls. J. Rheumatol. 2020, 47, 188-196. [CrossRef] [PubMed]

112. Siddle, K.J.; Tailleux, L.; Deschamps, M.; Loh, Y.H.E.; Deluen, C.; Gicquel, B.; Antoniewski, C.; Barreiro, L.B.; Farinelli, L.; Quintana-Murci, L. Bacterial Infection Drives the Expression Dynamics of microRNAs and Their isomiRs. PLoS Genet. 2015, 11, e1005064. [CrossRef] [PubMed]

113. Telonis, A.G.; Magee, R.; Loher, P.; Chervoneva, I.; Londin, E.; Rigoutsos, I. Knowledge about the presence or absence of miRNA isoforms (isomiRs) can successfully discriminate amongst 32 TCGA cancer types. Nucleic Acids Res. 2017, 45, 2973-2985. [CrossRef] [PubMed]

114. Parafioriti, A.; Cifola, I.; Gissi, C.; Pinatel, E.; Vilardo, L.; Armiraglio, E.; Di Bernardo, A.; Daolio, P.A.; Felsani, A.; D'Agnano, I.; et al. Expression profiling of microRNAs and isomiRs in conventional central chondrosarcoma. Cell Death Discov. 2020, 6. [CrossRef]

115. Li, S.C.; Liao, Y.L.; Ho, M.R.; Tsai, K.W.; Lai, C.H.; Lin, W.C. MiRNA arm selection and isomiR distribution in gastric cancer. Ser. Adv. Bioinforma. Comput. Biol. 2012, 13, S13. [CrossRef]

116. Babapoor, S.; Fleming, E.; Wu, R.; Dadras, S.S. A novel mir-451a isomir, associated with amelanotypic phenotype, acts as a tumor suppressor in melanoma by retarding cell migration and invasion. PLoS ONE 2014, 9, e120. [CrossRef]

117. Ni, H.; Dai, X.; Leng, X.; Deng, M.; Qin, Y.; Ji, Q.; Xu, C.; Li, J.; Liu, Y. Higher variety and quantity of microRNA-139-5p isoforms confer suppressive role in hepatocellular carcinoma. J. Cell. Biochem. 2018, 119, 6806-6813. [CrossRef]

118. Wang, S.; Zheng, Z.; Chen, P.; Wu, M. Tumor classification and biomarker discovery based on the 5 ' isomiR expression level. BMC Cancer 2019, 19, 127. [CrossRef]

119. Koi, Y.; Tsutani, Y.; Nishiyama, Y.; Ueda, D.; Ibuki, Y.; Sasada, S.; Akita, T.; Masumoto, N.; Kadoya, T.; Yamamoto, Y.; et al. Predicting the presence of breast cancer using circulating small RNAs, including those in the extracellular vesicles. Cancer Sci. 2020, 111, 2104-2115. [CrossRef]

120. Ibuki, Y.; Nishiyama, Y.; Tsutani, Y.; Emi, M.; Hamai, Y.; Okada, M.; Tahara, H. Circulating microRNA/isomiRs as novel biomarkers of esophageal squamous cell carcinoma. PLOS ONE 2020, 15, e0231116. [CrossRef]

121. Londin, E.; Magee, R.; Shields, C.L.; Lally, S.E.; Sato, T.; Rigoutsos, I. IsomiRs and tRNA-derived fragments are associated with metastasis and patient survival in uveal melanoma. Pigment Cell Melanoma Res. 2020, 33, 52-62. [CrossRef] [PubMed]

122. Liao, Z.; Li, D.; Wang, X.; Li, L.; Zou, Q. Cancer Diagnosis Through IsomiR Expression with Machine Learning Method. Curr. Bioinform. 2016, 13, 57-63. [CrossRef]

123. Plé, H.; Landry, P.; Benham, A.; Coarfa, C.; Gunaratne, P.H.; Provost, P. The Repertoire and Features of Human Platelet microRNAs. PLoS ONE 2012, 7. [CrossRef] [PubMed]

124. Geekiyanage, H.; Rayatpisheh, S.; Wohlschlegel, J.A.; Brown, R.; Ambros, V. Extracellular microRNAs in human circulation are associated with miRISC complexes that are accessible to anti-AGO2 antibody and can bind target mimic oligonucleotides. Proc. Natl. Acad. Sci. USA 2020, 117, 24213-24223. [CrossRef] [PubMed]

125. Lunavat, T.R.; Cheng, L.; Kim, D.K.; Bhadury, J.; Jang, S.C.; Lässer, C.; Sharples, R.A.; López, M.D.; Nilsson, J.; Gho, Y.S.; et al Small RNA deep sequencing discriminates subsets of extracellular vesicles released by melanoma cells-Evidence of unique microRNA cargos. RNA Biol. 2015, 12, 810-823. [CrossRef] [PubMed]

126. Koppers-Lalic, D.; Hackenberg, M.; Menezes, R. De Non-invasive prostate cancer detection by measuring miRNA variants (isomiRs) in urine extracellular vesicles. Oncotarget 2016, 7, 22566-22578. [CrossRef]

127. Karlsen, T.A.; Aae, T.F.; Brinchmann, J.E. Robust profiling of microRNAs and isomiRs in human plasma exosomes across 46 individuals. Sci. Rep. 2019, 9. [CrossRef]

128. Vaz, C.; Ahmad, H.M.; Bharti, R.; Pandey, P.; Kumar, L.; Kulshreshtha, R.; Bhattacharya, A. Analysis of the microRNA transcriptome and expression of different isomiRs in human peripheral blood mononuclear cells. BMC Res. Notes $2013,6,1$. [CrossRef] 